\title{
Why Public Health Interventions Need a Multidisciplinary Approach to Understand and Address Behaviours Effectively?
}

\author{
Agonnoudé Togbédji Maurice and David S Houeto* \\ National School of Public Health and Epidemiology, University of Parakou, Parakou, Benin Republic \\ ${ }^{\star}$ Corresponding author: David S Houeto, National School of Public Health and Epidemiology, University of Parakou, Parakou, Benin Republic
}

Received: June 25, 2021; Accepted: July 05, 2021; Published: July 09, 2021

\begin{abstract}
Although we have made significant efforts in controlling disease with strong improvements in, for instance, people's life expectancy, it is obvious that the 21st Century is full of health challenges such as unhealthy behaviors which are fueled by the way societies are organized so that there must be another focus on how we consider health and health issues in order to be more effective in addressing them. The objective of this reflection is to call upon the importance of a genuine understanding of health and ways of its improvement through interventions that address behaviors effectively while we are facing challenges that are different from the ones in the past centuries.
\end{abstract}

Keywords: Ecological approach of health; Transdisciplinary approach and effective behavior change interventions

\section{Introduction}

When considering health and health issues throughout centuries behind, it is obvious that improvements have been made with great achievements like the one on people's life expectancy. After strong efforts to control disease in the past, the $21^{\text {st }}$ Century is facing some different health challenges and unhealthy behaviors in a rapid changing world. The way societies are organized, dealing with development processes that are not getting all citizens onboard, the consequences of the climate change, the rapid demographic changes, globalization, and technological advances, among others, are impacting strongly health of populations [1]. If from the beginning, researchers could be skeptics with the World Health Organization (WHO) definition of health, nowadays there is great interest to consider that definition which leads to a comprehensive view of health so that by positioning people on a good level of the social ladder they will improve health and increase resilience [2].

The objective of this reflection is to call upon the importance of a genuine understanding of health and ways of its improvement through interventions that address behaviors effectively while we are facing challenges that are different from the ones in the past centuries.

\section{Ecological Model of Health}

According to WHO, "health is a state of complete physical, mental and social well-being and not merely the absence of disease or infirmity" [3]. This means that to be 'healthy', one should be well physically, mentally and socially. Health has been seen on different ways mainly with three major models: the biomedical model that views health as the absence of diseases or disorders; the behavioral model that views health as the product of making healthy lifestyle choices; and the socio-environmental model that views health as the product of social, economic and environmental determinants that provide incentives and barriers to the health of individuals and communities. This third model which is the more holistic way of viewing health is known also as biopsychosocial model or ecological model [4]. It emphasizes the linkages and relationships among multiple factors (determinants) affecting health. These determinants include biology, the social and physical environment, education, employment, and behavior. Dahlgren and Whitehead [5] drafted an example of the ecological model as shown in Figure 1 with one omitted factor, the general/local political context.

Gebbie et al. [1] explained that while an ecological model addresses the interactions and linkages among determinants of health, there are related concepts to it. The first is an ecological view of health which is a perspective that involves knowledge of the ecological model of determinants of health and an attempt to understand a specific problem or situation in terms of that model. The second is an ecological approach to health which is the one that develops multiple strategies to impact determinants of health relevant to the desired health outcomes. It is then to say that addressing public health challenges requires an ecological approach with its implications among which the transdisciplinary approach and health professionals who are fully prepared to work with others to improve health.

Why should one, in dealing with health issues, considering not the ecological approach and its emphasis on the social determinants of health? 


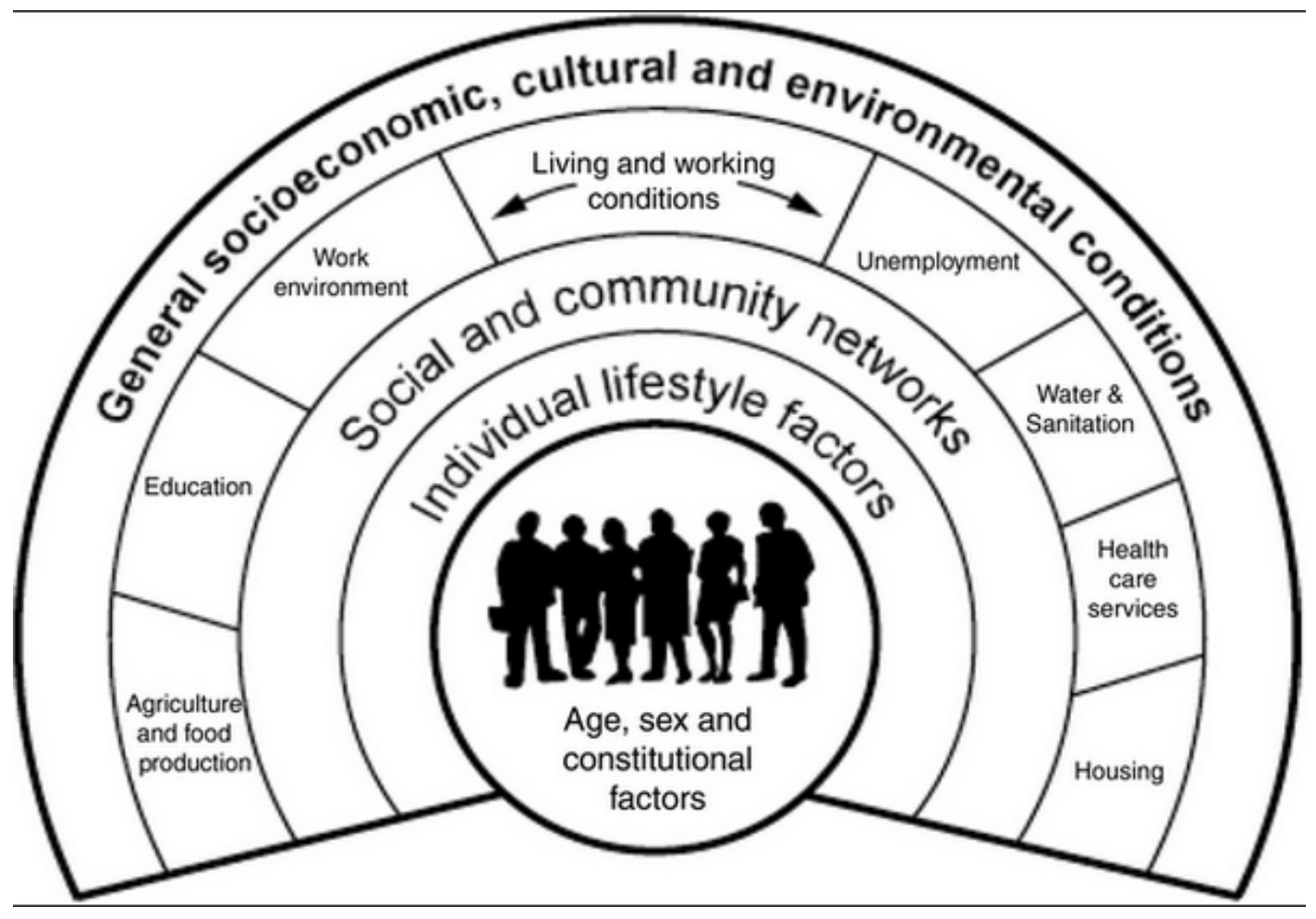

Figure 1: Example of the ecological model of health according to Dahlgren \& Whitehead [5].

\section{Social Determinants of Health and the Necessity for Transdisciplinary Interventions}

The health challenges we are facing in this $21^{\text {st }}$ Century which are, among others, the high level of consciousness of population's health with lot of investments but without consistent results could be compared to the ones that led Canadian Government in the 1970s to the Lalonde Report [6] with the important notion of determinants of health.

Determinants of health include: broad social, economic, cultural, and environmental conditions; living and working conditions; social, family, and community networks; individual behavior; individual traits such as age, sex, race, and biological factors, and the biology of disease [1]. According to Blake [7], health can be seen like an iceberg with multiple underpinning determinants that shape it, such as: i) Values including culture, biology and genetic endowment, employment and working conditions, income and social status; ii) Assumptions that comprise personal health practices and coping skills, social environments, social support networks; iii) Beliefs that encompass gender, healthy child development, physical environment, education; and iv) Health services.

A part from individual traits and the biological factors, it is obvious that health is influenced by multiple factors that are the results of how societies are organized, the Social Determinants of Health (SDHs). SDHs are the conditions in which people are (conceived), born, grow, live, work and age including mechanism in place to address diseases [8]. By defining SDHs that way, it is obvious that they are under the responsibility of multiple sectors outside of the health system and are shaped by the distribution of money, power and resources at global, national and local levels [8]. This helps understand that health results are not the responsibility of the health system alone and even, other sectors are more responsible than the health system for the health outcomes [9]. These health results (or health status) which is different across the population and between specific populations groups are mostly the responsibility of the social determinants of health through their distribution. These differences in health status due to how a society is organized to assure a fair distribution of SDHs are avoidable and known as health inequities. By questioning these differences, Evans and colleagues [10] showed the importance of SDHs in maintaining people healthy. Improving health status is then a task for multiple sectors which must work together to achieve better health.

As the WHO Commission on Social Determinants of Health (CSDH) [11] put it in its framework (Figure 2), a patient is a "messenger" telling the practitioner about its living conditions, because illness is a "feedback" on a given individual's social position. And social position is created by social, economic and political mechanisms, whereby populations are stratified according to income, education, occupation, gender, race/ethnicity and other factors. Socioeconomic positions in turn shape specific determinants of health status reflective of people's place within social hierarchies. Based on their respective social status, individuals experience differences in exposure and vulnerability to health-compromising conditions and behaviors. In other words, diseases and behaviors are a deeply social process. Their distribution lays bare society's structures of wealth and power, and the responses they elicit illuminate strongly held values [12]. According to Marmot [2], health and behavior follow a social gradient. A social gradient occurs when the frequency (e.g., of a health problem) increases steadily from the most advantaged to the least advantaged categories [2,13]. One 


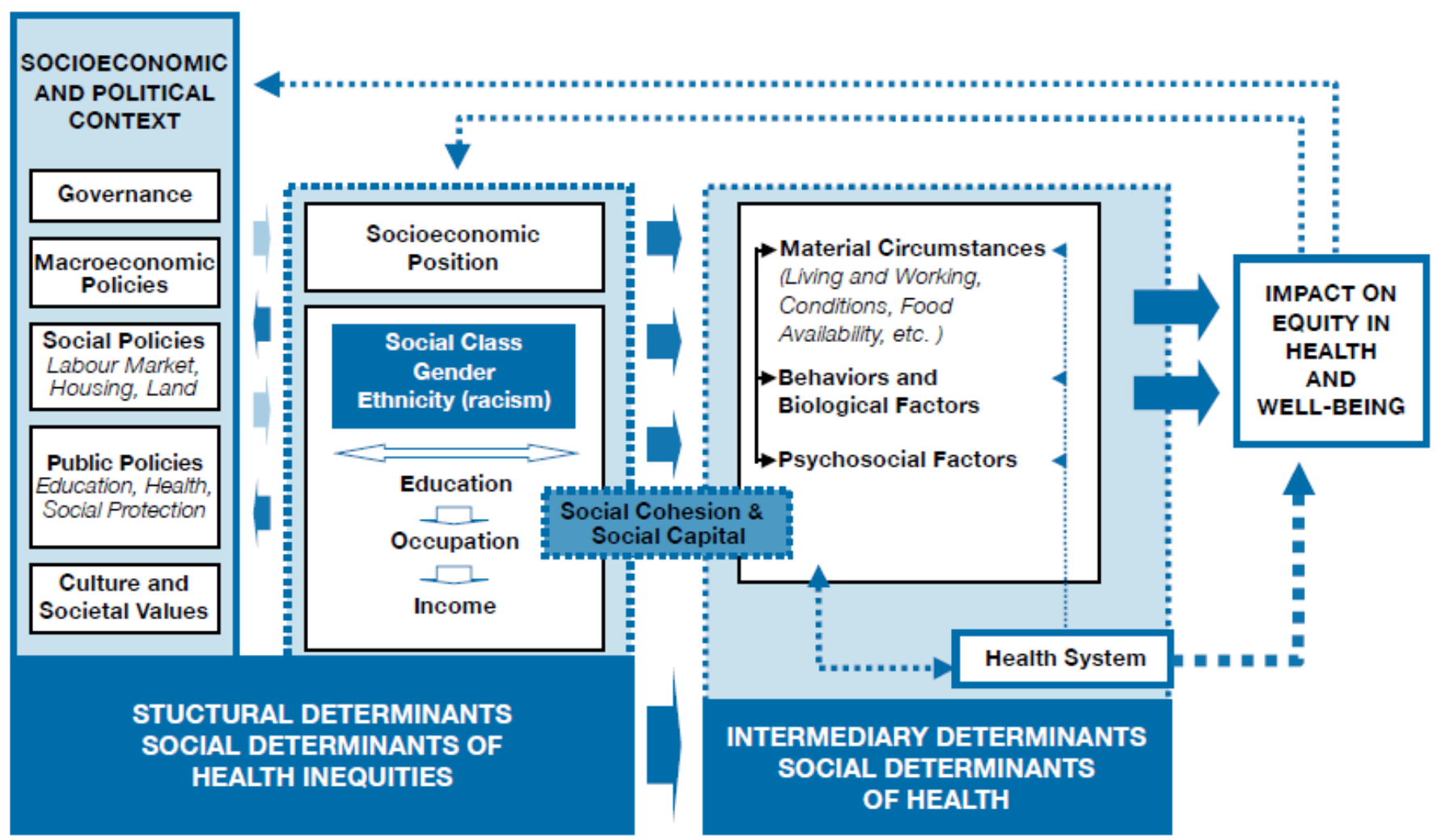

Figure 2: CSDH conceptual framework of social determinants of health inequities [11].

could understand what the CSDH report was saying: "Why treat people and send them back to the conditions that made them sick?" [8] There is absolutely a necessity to change the social position for sick people in order to be treating them adequately. To do so, it must be through a transdisciplinary approach because health system cannot afford to do that alone. That's why it is an unfinished work all the time people are treated and send back to the same conditions that made them sick.

What is then the implication of the ecological approach in addressing health issues and unhealthy behaviors?

\section{Implications of the Ecological Approach in Dealing with Health Issues and Unhealthy Behaviors}

With this ecological health perspective, health system has a huge responsibility which covers two main domains that are i) first and most important, the coordination of all other sectors through what WHO called "make every sector a health sector" [8], which means that it has to assume and act on the fact that health is all sectors' endeavor so that multidisciplinary approaches, when defining barriers and drivers and designing behavioral interventions, should be the corner stone. By so doing, SDHs are addressed, reducing social inequities, improving the living conditions of the populations and leading to healthy behaviors. ii) Second, disease management that has to be in the perspective of the ecological approach as shown in Table 1 according to Swannack and Appleby [14], considering necessarily the underpinning conditions that must be addressed in collaboration with other sectors.

As Gebbie and colleagues put it [1], health professionals must look beyond the biological risk factors that affect health and seek to also understand the impact on health of environmental, social, and behavioral factors. They must be aware of how these multiple factors interact in order to evaluate the effectiveness of their interventions. It is their responsibility to understand the theoretical underpinnings of the ecological model in order to develop research that further explicates

Table 1: Disease management with the ecological model compared to the biomedical model.

\begin{tabular}{|l|l|l|}
\hline \multicolumn{1}{|c|}{ Areas of disease management } & \multicolumn{1}{c|}{ Biomedical Model } & Ecological Model \\
\hline Considering factors & Only takes account of biological factors & Takes account of biological, psychological and social factors \\
\hline Views on what causes illness & All physical factors - pathogens, injury, physiological change & Multiple factors - physical, social and psychological \\
\hline Patient responsibility & No responsibility on the patient, because all factors are out of the patient's control & There is patient responsibility, because lifestyle has an influence \\
\hline Treatment style & Bodily interventions only & Whole person themes, mind and body \\
\hline Responsibility for treatments & Doctor only & Doctor and patient combined \\
\hline Role of psychology & No relationship with physical illness & Causal influence and consequence of physical illness \\
\hline
\end{tabular}

Source: Adapted from Swannack \& Appleby [14]. 
the pathways and interrelationships of the multiple determinants of health. It is through this understanding that health professionals will be able to more effectively address these $21^{\text {st }}$ century challenges we are facing, including globalization, scientific and medical technologies, and demographic transformations.

Frieden through his Health Impact Pyramid (Figure 3) [15] explained that interventions focusing on lower levels of the pyramid tend to be more effective because they reach broader segments of society and require less individual effort. The base of the pyramid is indicating interventions that have the greatest potential impact and represent efforts to address SDHs. The multisectoral aspect of the pyramid reinforces the maximum possible sustained public health benefit when implementing interventions at each of the levels. One of the levels of that pyramid is clear for what specifically is related to behavior change in stipulating that context must be changed to make individual's default decisions healthy. Behavior is not only individual's responsibility (Figure 4) [16-19].

Taket [20] in a paper entitled "Making partners-intersectoral action for health" clarified what the environment is all about, physical and socioeconomic and in link with the health gradient: poverty, poor housing, unemployment, inadequate food and nutrition, lack of education, environmental health hazards. It is then clear that the weapon we do have to succeed understanding and addressing effectively behaviors is the multisectoral approach in which the health sector has to play an important role of coordinating other sectors through what WHO calls "Action across sectors" [16].

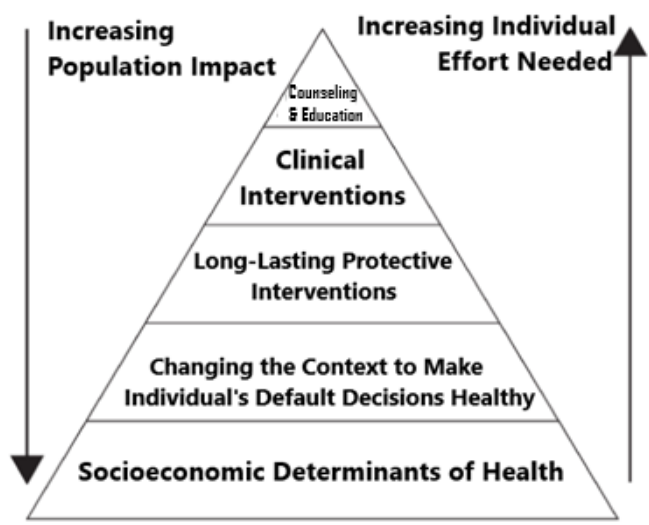

Figure 3: The Health Impact Pyramid [15]

\section{Complementary approaches to prevention}

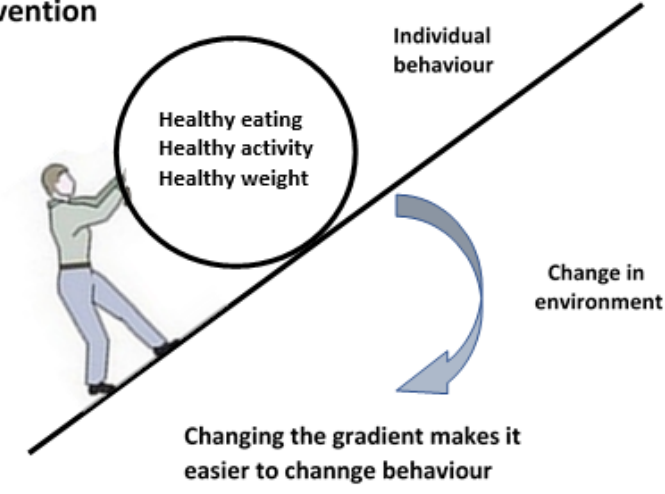

Figure 4: Complementary approaches to prevention [19].

\section{Conclusion}

Health cannot be viewed as a simple phenomenon; it is a complex one and then needs that multiple sectors gathered together to solve issues related to it because of that complexity. Working for healthy choices and effective behavior change interventions requires then a multidisciplinary approach that implies the whole-of-society approach with a leading role at local government level and communities equipped with health literacy.

\section{References}

1. Gebbie K, Rosenstock L, Hernandez LM (2003) Who will keep the public healthy? Educating public health professionals for the $21^{\text {st }}$ Century. Committee on Educating Public Health Professionals for the $21^{\text {st }}$ Century. Board on Health Promotion and Disease Prevention, The National Academies Press, Washington D.C., USA. [Crossref]

2. Marmot M (2004) Status syndrome: How your place on the social gradient directly affects your health. Bloomsbury, London, UK.

3. World Health Organization (WHO). Preamble to the Constitution of WHO as adopted by the International Health Conference, New York, 19 June - 22 July 1946; signed on 22 July 1946 by the representatives of 61 States (Official Records of WHO, no. 2, p. 100) and entered into force on 7 April 1948.

4. Houéto D, Laverack G (2014) Promotion de la santé et autonomisation dans le contexte africain, Rossendale Books Editions, Raleigh, USA.

5. Dahlgren G, Whitehead M (1991) Policies and strategies to promote social equity in health. Stockholm: Institute for the Futures Studies.

6. Lalonde M (1974) A New Perspective on the Health of Canadians. Ottawa, ON: Ministry of Supply and Services.

7. Blake (2013) Likely healthy: Public health aims to increase the likelihood of good health at the population level.

8. World Health Organization (WHO) (2008) Closing the gap in a generation: Health equity through action on the social determinants of health. Final Report of the WHO Commission on Social Determinants of Health. Geneva, Switzerland.

9. Kottke ET, Pronk PN (2009) Taking On the Social Determinants of Health: A Framework for Action.

10. Evans GR, Morris L, Theodore R (1994) Why are some people healthy and others not? The determinants of health of populations. New York (USA): Aldine de Gruyter, Social institutions and social change series.

11. Solar O, Irwin A (2010) A conceptual framework for action on the social determinants of health. Social Determinants of Health Discussion Paper 2 (Policy and Practice). World Health Organization, Geneva, Switzerland.

12. Jones SD, Podolsky HS, Greene AJ (2012) The Burden of Disease and the Changing Task of Medicine. The New England Journal of Medicine 366: 2333-2338. [Crossref]

13. Leclerc $\mathrm{A}$, Kaminski M, Lang $\mathrm{T}$ (2008) Inégaux face à la santé : du constat à l'action. Institut National de la Santé et de la Recherche Médicale, Ed La Découverte.

14. Swannack M, Appleby B. Models of Health. 2020. Available from: https://simplemed co.uk/subjects/population-and-social-science/models-of-health [accessed on 10 December 2020].

15. Frieden RT (2010) A Framework for Public Health Action: The Health Impact Pyramid. American Journal of Public Health 100: 590-595. [Crossref]

16. World Health Organization (WHO). Ninth Global Conference on Health Promotion: "Health in the Sustainable Development Goals" Shanghai, China, 21 to 24 November 2016

17. World Health Organization (WHO). Shanghai Consensus on Healthy Cities 2016. Healthy Cities Mayors Forum. Ninth Global Conference on Health Promotion, Shanghai, China, 21 November 2016.

18. World Health Organization (WHO). Jakarta Declaration on Leading Health Promotion into the $21^{\text {st }}$ Century. The Fourth International Conference on Health Promotion: New Players for a New Era - Leading Health Promotion into the $21^{\text {st }}$ Century, meeting in Jakarta from 21 to 25 July 1997. 
David S Houeto (2021) Why Public Health Interventions Need a Multidisciplinary Approach to Understand and Address Behaviours Effectively?

19. Puska P (2001) Health-related lifestyles are the key: round table discussion/Pekka Puska. Bulletin of the World Health Organization: the International Journal of Public Health 79: 985-998.
20. Taket AR (1990) Making partners-intersectoral action for health. In: Proceedings and outcome of a joint working group on intersectoral action for health, Utrecht, 30 November-2 December 1988. The Hague, Ministry of Welfare, Health and Cultural Affairs.

\section{Citation:}

Maurice AT, Houeto DS (2021) Why Public Health Interventions Need a Multidisciplinary Approach to Understand and Address Behaviours Effectively? Prev Med Epid Public Heal Volume 2(4): 1-5. 